\title{
Foreword by the Editors
}

European Surgical Research was founded in 1969 by leading representatives of the European Society for Experimental Surgery. In 1978, this society was named European Society for Surgical Research (ESSR); at the same time, the journal, being no longer the Society's official journal, has adopted the subtitle 'Clinical and Experimental Surgery'.

On the occasion of the 20th anniversary of the initiating society, the editors of European Surgical Research were attracted by the idea of Professor Roger Benichoux, founder and honorary president of ESSR, to prepare a special issue containing articles covering the fields of interest of the past presidents of ESSR. The resulting 'Festschrift' mirrors the wide spectrum of interests entertained within the society since its inception. We have great pleasure in dedicating this 'Festschrift' to the members of the European Society for Surgical Research as well as to the readers of the journal.

This 'Festschrift' outlines pathways of surgical research and emphasizes the role of Europeans in the promotion of the surgical sciences during the past 20 years. Without doubt, organ replacement and organ substitution by biological or technical means presented the most stimulating challenge for sur-

gical research. Of equal importance were coronary surgery, surgical pathophysiology and shock research, whereas gastrointestinal surgery, ever since the pioneering work of Bill-roth, has remained a tradition of surgical research in Europe. At the time of foundation, the officers of the society as well as the members of the editorial board of this journal were convinced that both organizations should provide a forum to discuss the entire spectrum of surgical research in Europe. Today we have to appreciate that the growth of surgical research has brought along a diversification into research subspecialties as reflected by newly established organizations, such as the European Society for Artificial Organs, the European Shock Society and the European Society for Organ Transplantation.

Even though these societies and their respective publications fulfill important tasks for the specialists themselves, this evolution will hasten the splitting of surgical research into subspecialties with the immanent danger of loosing contact and exchange of opinions between the individuals within the various surgical subspecialties. Furthermore, for the specialists, it will become more and more dif-

138

Foreword by the Editors

ficult to keep track in terms of general developments in surgical research in its broadest sense.

The European Society for Surgical Research and the editors of this journal have always been aware of this tendency and the problems resulting from it. For these reasons, both institutions have always had a continuous commitment to provide a forum for mutual exchange of ideas persued by specialists in the various fields of surgical research. The roots of these commitments are not only scientific and cultural, but, equally important, political in nature: the more the world develops into power blocks, the more it seems important to protect the cultural inheritance by uniting the forces within Europe. 
We do see the Society for Surgical Research in its 21st year and the journal having published 17 annual issues as a vivid expression of the European efforts in the field of surgical research. With this special issue, we would like to inform the readership about changes within the editorial board. Since the manuscripts submitted to this journal are dealing more and more with highly diversified and specialized subjects, it was felt necessary to expand the spectrum of expertise beyond the scope covered by the original editorial board. At the same time, some of the members of our editorial board had expressed their wish to retire from their work for the journal.

As editors-in-chief, we do regret that H.A.F. Dudley, London; U.F. Gruber, Basel; J.-N. Maillard, Colombes, and N.A. Mathe-son, Aberdeen, will no longer be available for regular consultation. These colleagues have been members of the editorial board from the very beginning and they have provided support and expertise to the journal until today.

Among the members leaving, U.F. Gruber was instrumental in founding the journal in 1969. We are deeply indebted to the colleagues leaving the editorial board and we do express our sincere gratitude for their continuous and excellent collaboration without which the journal would not have flourished and could not have reached its present scientific standard and world-wide recognition.

We are fortunate to welcome the new colleagues who have joined the editorial board at the beginning of 1986 enlarging it in number, but more importantly in expert knowledge in the most rapidly developing fields, namely surgical pathophysiology, cardiovascular surgery, gastrointestinal surgery, sepsis/peritonitis, pancreas/liver, immunologi-cal aspects of surgery, microsurgery, colorec-tal disease, surgical oncology, endocrinology, artificial organs and last but not least biosta-tistics.

New members of the editorial board are:

J. Ahonen, Helsinki/Finland

H.G. Beger, Ulm/FRG

A. Bismuth, Villejuif/France

U. Haglund, Malmö/Sweden

W.P. Klövekorn, Munich/FRG

M. Lempinen, Helsinki/Finland

D. Loisance, Créteil/France

R. Lozano, Zaragoza/Spain

H.E. Myrvold, Trondheim/Norway

R. Schosser, Heidelberg/FRG

I. Taylor, Southampton/UK

R.W. Wilson, Boston/USA

We are thankful to these colleagues for providing both, their experience and their precious time for the benefit of European Surgical Research in the future.

Munich/Heidelberg W. Brendel

January $1986 \quad$ K. Messmer

(editors-in-chief) 